\title{
Bulk Heterojunction Solar Cell Devices Prepared with Composites of Conjugated Polymer and Zinc Oxide Nanorods
}

\author{
Nguyen Tam Nguyen Truong, Hoa Nguyen, Phuc Huu Tran Le, \\ Chinho Park, and Jae Hak Jung
}

School of Chemical Engineering, Yeungnam University, 280 Daehak-Ro, Gyeongsan 712-749, Republic of Korea
Correspondence should be addressed to Chinho Park; chpark@ynu.ac.kr and Jae Hak Jung; jhjung@ynu.ac.kr

Received 27 October 2016; Revised 5 January 2017; Accepted 11 January 2017; Published 13 February 2017

Academic Editor: Mayakrishnan Gopiraman

Copyright (c) 2017 Nguyen Tam Nguyen Truong et al. This is an open access article distributed under the Creative Commons Attribution License, which permits unrestricted use, distribution, and reproduction in any medium, provided the original work is properly cited.

\begin{abstract}
$\mathrm{ZnO}$ nanorods (Nrods) with $\sim 20-50 \mathrm{~nm}$ lengths were synthesized using an aqueous solution of zinc acetate and glacial acetic acid. Bulk heterojunction solar cells were fabricated with the structure of indium tin oxide (ITO)/polyethylenedioxythiophene doped with polystyrene-sulfonic acid (PEDOT:PSS)/ZnO-Nrods + polymer/electron transport layer (ETL)/Al. Current densityvoltage characterization of the resulting cells showed that, by adding an ETL and using polymers with a low band gap energy, the photoactive layer surface morphology and the device performance can be dramatically improved.
\end{abstract}

\section{Introduction}

Semiconducting inorganic nanocrystals (NCs) with different shapes such as nanowires, nanospheres, nanosheets, nanotetrapods, and nanorods have attracted significant attention in the field of materials science owing to their promising applications in optoelectronic devices such as inorganic and organic light emitting diodes and photovoltaic devices [1-3]. The first hybrid photovoltaic device using CdS and CdSe NCs was reported by Greenham et al. [4]. Since then, inorganic semiconducting NCs, such as PbS, CdS, and CdSe NCs, with different structures, sizes, shapes, and morphological characteristics have been investigated and applied for hybrid bulk heterojunction (BHJ) photovoltaic devices [5-7]. However, note that the above materials, including cadmium, lead, and indium, are either nonabundant or toxic, so these materials cannot contribute significantly to future green, eco-friendly technologies and renewable energy. Therefore, low-cost, nontoxic, and eco-friendly semiconducting materials are being extensively explored as alternatives to existing materials for hybrid solar cells, even though they might produce lower power conversion efficiencies. Metal oxide nanostructures in particular have attracted considerable attention for their potential applications, for example, in solar cells, electroluminescent devices, electrochromic windows, and chemical sensors [8-11]. The metal oxide nanostructures used in these applications must have a large surface area and good photoelectronic, electrochemical, and structural properties.

$\mathrm{ZnO}$ is a wide-band-gap semiconductor with an energy gap of $3.37 \mathrm{eV}$ at room temperature. Many different $\mathrm{ZnO}$ structures have been investigated for solar cell applications [12-14]. Since $\mathrm{ZnO}$ shows different chemical and physical properties depending on the size and shape of NCs, it might easily form a penetration network between particles; this is greatly beneficial for charge carrier transportation.

Hybrid polymer-ZnO NCs have been studied $[15,16]$, and $\mathrm{ZnO}$ NCs have been investigated as the n-type material in cells as they are cheap and eco-friendly and can be synthesized with high purity and crystallinity at low temperatures. However, results show that the device efficiency in these previous papers was lower (efficiency $\sim 1.6 \%$ ) than that of other hybrid BHJ solar cells because of unoptimized photoactive surface morphology, light absorption, and charge transport (collect) efficiency.

In order to enhance the device efficiency, the effects of various processing conditions, such as the absorption 
coefficient of the materials, the thickness of the photoactive layer, and the charge carrier transports, were studied. The active layer should absorb as many photons as possible to generate the electron-hole pairs. Therefore, the thickness and surface morphology of the active layer should be well controlled and optimized. The contact should collect as many charge carriers as possible from the $\mathrm{p}-\mathrm{n}$ junction. Therefore, the hole transport layer (HTL) and electron transport layer (ETL) should be added and optimized.

Conducting polymers such as poly(2-methoxy-5-( $3^{\prime}, 7^{\prime}-$ dimethyloctyloxy)-1,4-phenylenevinylene) (MDMO PPV) and poly(3-hexylthiophene-2,5-diyl)(P3HT) have been employed in devices [17]. However, these polymers have a large band gap (from $\sim 2$ to $2.8 \mathrm{eV}$ ), which prevents the light absorption in the red region and near-IR region of the solar spectrum. Radiation with a long wavelength $(>700 \mathrm{~nm})$ passes through the diodes and makes a small contribution to the photocurrent. Therefore, new polymers with a low band gap of 1.3-1.4 eV (such as PCPDBTB and PTB7) were investigated; polymers with low band gap energy enable absorption of more photons with a long-wavelength spectrum.

In this study, high-quality and pure $\mathrm{ZnO}$ nanorods (Nrods) were synthesized and characterized for hybrid BHJ solar cell applications. Devices based on a blend of polymer and $\mathrm{ZnO}$-Nrod NPs were fabricated. The device parameters including length of $\mathrm{ZnO}$ nanorods, absorption, and active layer surface morphology were investigated and characterized. The $\mathrm{BHJ}$ device based on a high-light-absorption polymer and $\mathrm{ZnO}$ nanorods exhibited extended red light harvesting up to $900 \mathrm{~nm}$, in contrast to the typical $350-$ $800 \mathrm{~nm}$ absorption in the case of P3HT and PCPDTBT. The improved $\mathrm{BHJ}$ device presents the possibility of fabricating low-cost, nontoxic, and eco-friendly inorganic/organic hybrid $\mathrm{BHJ}$ solar cells.

\section{Experimental}

In the typical procedure, $300 \mathrm{~mL}$ of $0.02 \mathrm{M}$ zinc acetate aqueous solution was mixed with $1 \mathrm{~mL}$ glacial acetic acid in a round-bottomed flask equipped with a refluxing device. The solution was heated to $100^{\circ} \mathrm{C}$ with vigorous stirring, and then, about $0.8 \mathrm{~g}$ of $\mathrm{NaOH}$ solid (analytical grade, platelets) was rapidly added to the above boiling solution until the $\mathrm{pH}$ value of the mixture reached 6-7, at which point, a large amount of white precipitate was produced. After cooling to room temperature, the precipitate was centrifuged, washed once with distilled water and three times with absolute ethanol, and dried in air at $60^{\circ} \mathrm{C}$. The resulting $\mathrm{ZnO}$-Nrods were $\sim 20-$ $50 \mathrm{~nm}$ in length.

UV-Vis-NIR spectrophotometry (Cary 5000, Varian) over 200-800 nm, X-ray diffraction (XRD), and transmission electron microscopy (TEM) were used to characterize the optical and structural properties of the $\mathrm{ZnO}$ nanorods. The UV-vis (Cary 5000) spectra of the $\mathrm{ZnO}$ nanorods were obtained using quartz cells with a $1.0 \mathrm{~cm}$ path length. The samples were prepared by dispersing the nanoparticles in ethanol before the measurements. The size and shape of the NCs were estimated from the high-resolution transmission electron microscopic (HR-TEM, H-7600) images. The thickness of active layers was measured by using AlphaStep D-500 Stylus Profiler. The current density-voltage $(J-V)$ characteristics of the solar cells were examined under AM1.5G illumination using a solar simulator (Keithley 69911).

Devices having the structure of glass/ITO/PEDOT:PSS/ (ZnO-Nrod + polymer)/ETL/Al were then fabricated. A thin $(\sim 70 \mathrm{~nm})$ layer of PEDOT:PSS as HTL was spin-coated at $4000 \mathrm{rpm}$ for $30 \mathrm{~s}$ onto cleaned indium tin oxide- (ITO-) coated glass substrates and dried at $120^{\circ} \mathrm{C}$ for $20 \mathrm{~min}$. The composite solution of $\mathrm{ZnO}-\mathrm{Nrods}$ and polymers such as poly(3-hexylthiophene-2,5-diyl)(P3HT), poly[2,6-

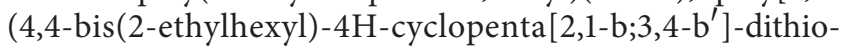
phene)-alt-4,7-(2,1,3-benzothiadiazole)] [PCPDTBT], and (poly(\{4,8-bis[(2-ethylhexyl)oxy]benzo[1,2-b:4,5-b'] dithiophene-2,6-diyl\}\{3-fluoro-2-[(2ethylhexyl)carbonyl] thieno [3,4b] thiophenediyl\}) [PTB7]) was dropped and spin-coated onto the preformed PEDOT:PSS layers. Then the samples were dried at $140^{\circ} \mathrm{C}$ for $30 \mathrm{~min}$ and a thin layer of $\mathrm{ZnO}$ nanoparticles as the HTL was spin-coated onto the top of active layer. Finally, a $\sim 90 \mathrm{~nm}$ thick $\mathrm{Al}$ electrode layer was deposited on the films by thermal evaporation to complete the devices. Figure 1 shows the schematic diagram of devices fabricated in this study, along with the materials structure.

\section{Results and Discussion}

Figures 2(a) and 2(a) (inset) show HR-TEM and TEM images of the $\mathrm{ZnO}$ nanorods. Nanorods in the range of 10-15 $\mathrm{nm}$ in diameter and in range of $20-50 \mathrm{~nm}$ in length had been formed. The lattice fringes of nanorod are clearly visible and no disruption inside the nanorods was presented, indicating that the $\mathrm{ZnO}$ nanorods obtained in this work were of high quality. Figure 2(b) is the UV-vis absorption spectra of $\mathrm{ZnO}-\mathrm{Nrods}$ dispersed in ethanol solution. It shows a strong absorption peak in the range of $300-400 \mathrm{~nm}$ and the peak was observed at the $369 \mathrm{~nm}$.

Figure 2(c) shows the XRD diffraction pattern of $\mathrm{ZnO}$ nanorods and it can be observed that all peaks at $2 \theta$ values of $31.5,34.3,36.4,47.5,56.5,62.8,67.9$, and 72.5 can be indexed to the (100), (002), (101), (102), (110), (103), (112), and (004) planes of zinc oxide nanorods, respectively. The position of several XRD peaks matched very well with the standard diffraction data (Joint Committee for Power Diffraction Set (JCPDS) database number 80-0075). The diffraction peaks are quite similar to those of a bulk $\mathrm{ZnO}$ with the hexagonal structure and the strongest peaks were (100), (002), and (101) for the randomly oriented direction samples.

The surface morphology and roughness of the $\mathrm{ZnO} /$ P3HT photoactive layer having different concentration of $\mathrm{ZnO}-\mathrm{Nrods}$ at the fixed composite loading amount of $5 \mathrm{mg} / \mathrm{mL}$ were studied by AFM. The ZnO-Nrod concentrations were varied from 0 to $90 \mathrm{wt} \%$. The $J-V$ characteristics of the devices were measured at AM1.5G conditions by using a solar simulator, and the resulting device parameters such as the short circuit current density $\left(J_{\text {sc }}\right)$, open circuit voltage $\left(V_{\mathrm{oc}}\right)$, fill factor $(\mathrm{FF})$, and power conversion efficiency $(\eta)$ are compared in Figure 3(b). Interestingly, among the cells with the $\mathrm{ZnO}-\mathrm{Nrod} / \mathrm{P} 3 \mathrm{HT}$ composites, the maximum power conversion efficiency was achieved for the cell with 


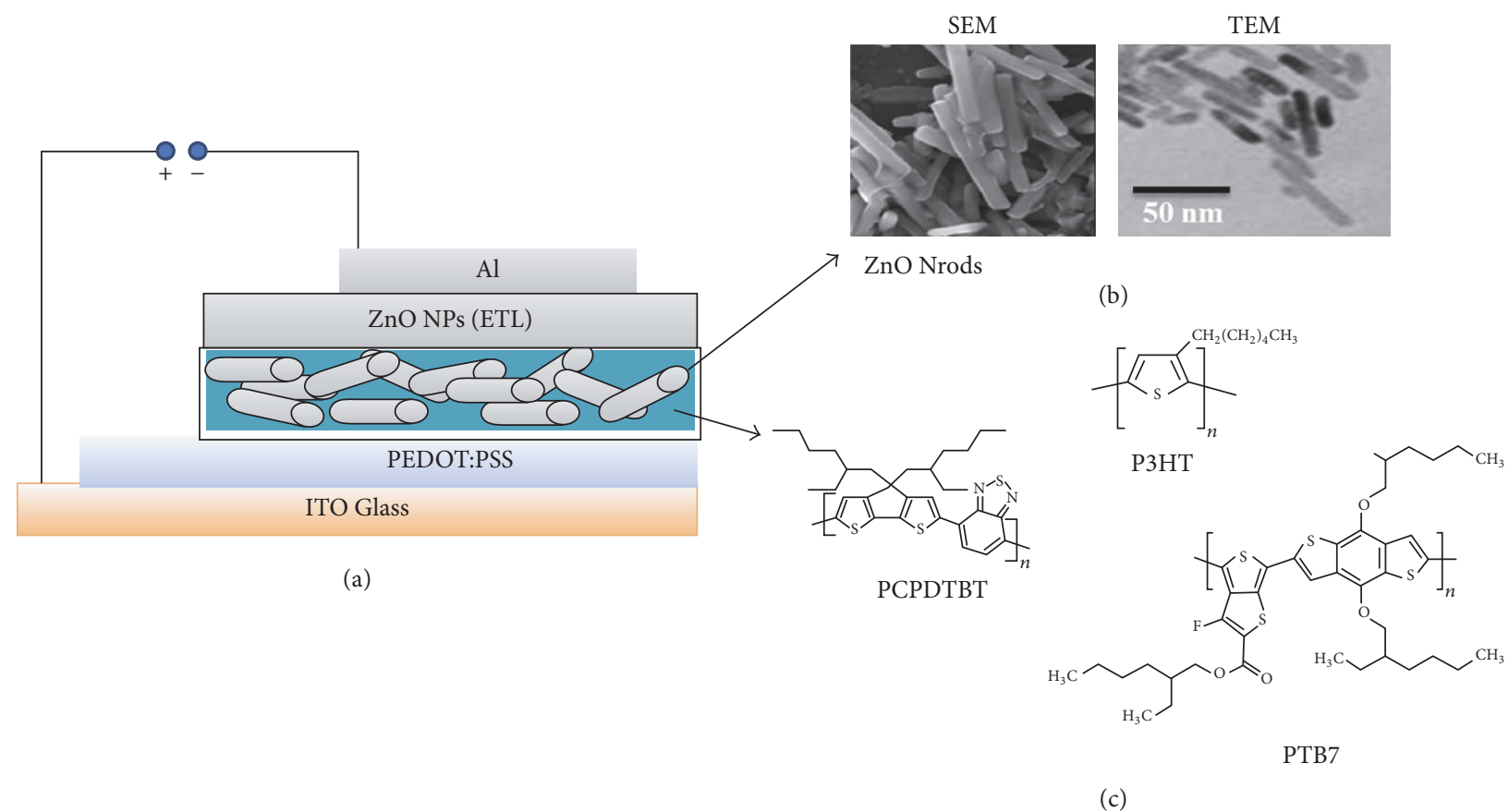

FIGURE 1: Schematic diagrams of (a) bulk heterojunction (BHJ) solar cells and (b) polymers and ZnO nanorods structure.

$60 \mathrm{wt} \% \mathrm{ZnO}-\mathrm{Nrods}$. This is consistent with the AFM surface roughness results, as shown in Figure 3(a).

Figure 3(b) (B and D) shows the monotonic increase in $J_{\mathrm{sc}}$ and efficiency with the increase in the $\mathrm{ZnO} /[\mathrm{ZnO}+$ $\mathrm{P} 3 \mathrm{HT}]$ (\%) loading amount. It is confirmed that the increase in the Nrod concentration enhances the charge transport and collection efficiency by generating a larger photoactive interface area and reducing the carrier recombination rate; hence, the Nrods and P3HT polymer act as the electron and hole transport materials, respectively. Further, the fill factor and open circuit voltages likely remain unchanged until the Nrod concentration reached $60 \mathrm{wt} \%$ and then increased slightly. However, the results indicated that despite the slight increase in the device parameters as a function of the loading amount, their absolute values are still lower than the best reported values [15].

In case of standard and inverted device structures, the active layer materials have the same function with four main processes: (1) photon absorption from sunlight, (2) conversion of photons to free charge carriers, (3) transport of the electrons and holes to the contacts, and (4) extraction of these charge carriers at the contacts to generate useful power. In order to enhance the device performance, however, a $\mathrm{BHJ}$ should include both the HTL and ETL [18-20]. The overall reported power conversion efficiency using the HTL and ETL ranges from $2 \%$ to about $4 \%$. In this study, the PEDOT:PSS ( $70 \mathrm{~nm}$ thickness) was used as the HTL and the ZnO NPs deposition were selected as the ETL, as shown in Figure 1. One of the most important parameters that affect the device performance is the morphology (and, consequently, the surface roughness) of the $\mathrm{ZnO}$ layer. In this section, attention will be focused on the possible influences of the ETL layer surface morphology on device fabrication with various thicknesses.
TABLE 1: Electron transport layer's surface morphology as the junction of spin-speed of 1000, 2000, 3000, and 4000 round per minute.

\begin{tabular}{lcc}
\hline $\begin{array}{l}\text { ZnO (ETL) spin } \\
\text { speed }(\mathrm{rpm})\end{array}$ & $\begin{array}{c}\text { Roughness }(\mathrm{RMS}) \\
(\mathrm{nm})\end{array}$ & Contact angles $\left(^{\circ}\right)$ \\
\hline 1000 & $\sim 5.92$ & $\sim 77.64$ \\
2000 & $\sim 4.6$ & $\sim 56.64$ \\
3000 & $\sim 3.91$ & $\sim 44.61$ \\
4000 & $\sim 2.86$ & $\sim 38.61$ \\
\hline
\end{tabular}

Figure 4(a) shows the thickness of $\mathrm{ZnO}$ layer as the function of spin coating speed. The coating spin speed was varied in range of 1000 rounds per minute (rpm) to $4000 \mathrm{rpm}$. The figure shows that when the spin speed is increased, the $\mathrm{ZnO}$ thickness is decreased. At $4000 \mathrm{rpm}$, the $\mathrm{ZnO}$ film thickness is around $\sim 30 \mathrm{~nm}$. The effects of ZnO ETL on the morphology of the photoactive surface as a function of the spin speed were studied by AFM (roughness mean square (RMS)) and video contact angle measurement, as shown in Figure 4(b).

Figure $4(\mathrm{~b}),(\mathrm{A}-\mathrm{D})$ and $(\mathrm{E}-\mathrm{K})$, shows the surface roughness (RMS) and the contact angle of photoactive layer as a function of the spin coating speed. We observed that when the speed is increased, the RMS and contact angle are decreased, as shown in Table 1. At the speed of $4000 \mathrm{rpm}$, the RMS and contact angle of the photoactive layer surface are $2.86 \mathrm{~nm}$ and $38.64^{\circ}$, respectively.

In particular, with the decrease in the thickness, the morphology of the ZnO ETL changed from a rough surface to a smoother surface to improve the contact between the photoactive layer and back contact layer. 


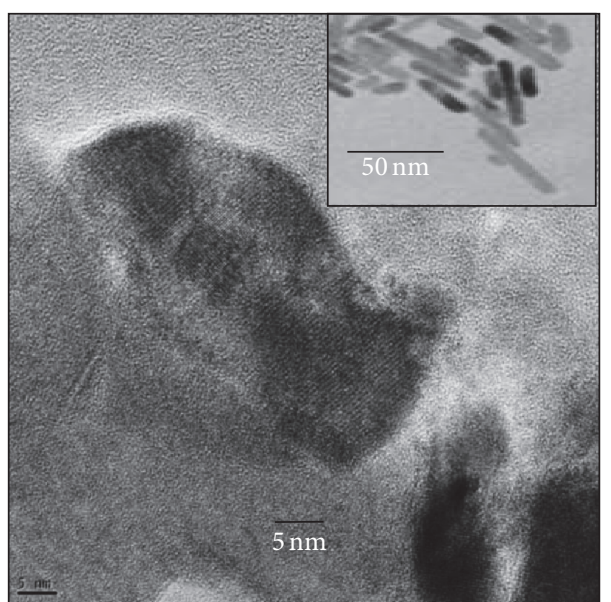

(a)

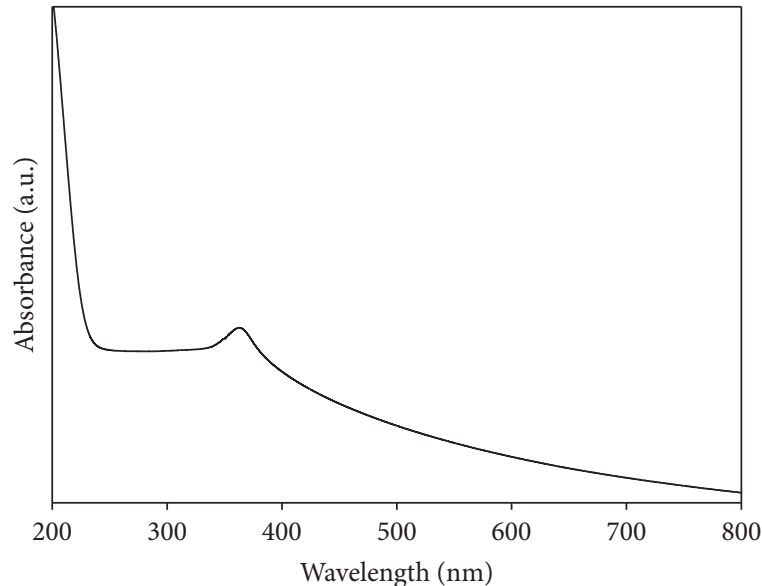

(b)

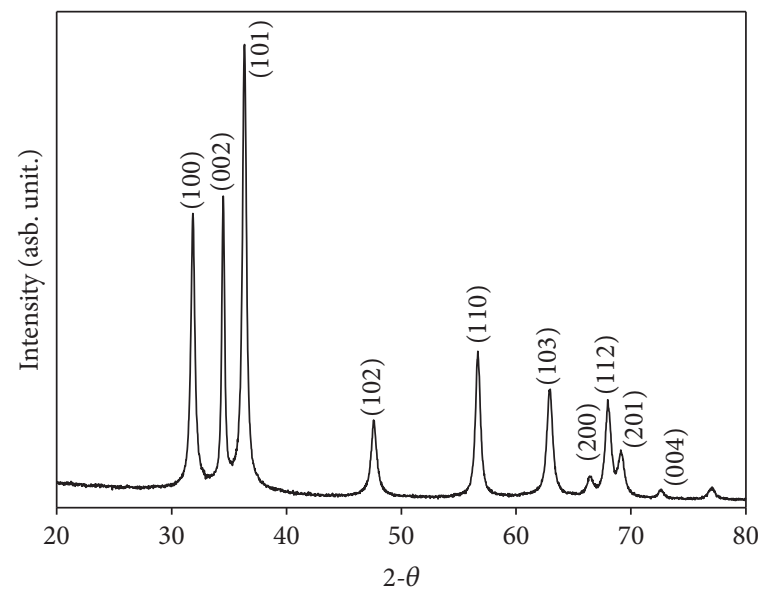

(c)

FIGURE 2: (a) High-resolution electron micrograph (HR-TEM) of single-crystal nanorods and (a) (inset) TEM image of ZnO nanorods; (b) UV-Vis absorption spectra of $\mathrm{ZnO}$ nanorods; (c) the XRD diffraction of the $\mathrm{ZnO}$ nanorods.

Figure 5 shows the effects of the $\mathrm{ZnO}$ layer (ETL) on the solar cell performance. In this study, $\mathrm{ZnO}$ nanoparticles were synthesized by laboratory, as shown in Figure 5 (inset). Figure 5 (inset (a)) shows the TEM image of ZnO NPs with a size of $\sim 3-5 \mathrm{~nm}$. Figure 5 (inset (b)) shows the ZnO NPs/ITO thin film (spin speed of $4000 \mathrm{rpm}$ ) with the surface roughness of $\sim 2 \mathrm{~nm}$. In a device without the ETL, the power conversion efficiency is about $\sim 1.71 \%\left(J_{\mathrm{sc}} \sim 8.64 \mathrm{~mA} / \mathrm{cm}^{2}\right)$, but in a device with $\mathrm{ZnO}$ ETL, the efficiency is increased to $\sim 2.25 \%\left(J_{\mathrm{sc}} \sim\right.$ $10.26 \mathrm{~mA} / \mathrm{cm}^{2}$ ); the detailed device parameters are shown in Table 2. The improvement in the device performance especially in the efficiency and current density might be attributed to the increase in the charge collection efficiency and to the reduction in the charge recombination from the $\mathrm{p}-\mathrm{n}$ photoactive interface to the contact layers [21,22].

The optical absorption spectra of $\mathrm{ZnO}$-Nrods and ( $\mathrm{ZnO}-$ Nrod/P ${ }_{3} \mathrm{HT}$, ZnO-Nrod/PCPDTBT, and ZnO-Nrod/PTB7) thin films were confirmed, as shown in Figure 6 (inset). The absorption spectra of $\mathrm{ZnO}-\mathrm{Nrods}$ correspond to the
TABLE 2: Effects of high light absorption polymers on the device' parameters such as short circuit current density $\left(J_{\mathrm{sc}}\right)$, open-circuit voltage $\left(V_{\mathrm{oc}}\right)$, fill factor $(\mathrm{FF})$, and power conversion efficiency $(\eta)$.

\begin{tabular}{lcccc}
\hline Polymers & $V_{\text {oc }}(\mathrm{V})$ & $J_{\text {sc }}\left(\mathrm{mA} / \mathrm{cm}^{2}\right)$ & $\mathrm{FF}(\%)$ & $\eta(\%)$ \\
\hline P3HT & 0.6 & 10.26 & 36 & 2.25 \\
PCBDTBT & 0.5 & 12.62 & 35 & 2.54 \\
PBT7 & 0.54 & 14.9 & 32 & 2.90 \\
\hline
\end{tabular}

absorption band of $350-400 \mathrm{~nm}$. The absorption spectra of $\mathrm{ZnO} / \mathrm{P}_{3} \mathrm{HT}$ thin films correspond to the absorption band region of $450-650 \mathrm{~nm}$. Therefore, lower-band-gap energy polymers were designed to enhance the sunlight absorption. The absorption bands of the ZnO-Nrod/PCPDTBT and $\mathrm{ZnO}-\mathrm{Nrod} / \mathrm{PTB} 7$ correspond to the spectra region of $350-850 \mathrm{~nm}$. In the BHJ solar cells, the polymer absorbs a narrow range of wavelengths in the visible spectrum. Since $V_{o c}$ is determined by the energy gap between the 


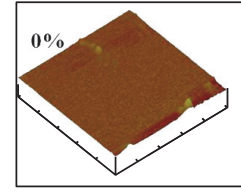

$\mathrm{RMS} \sim 4 \mathrm{~nm}$

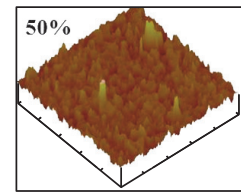

RMS $~ 5.8 \mathrm{~nm}$

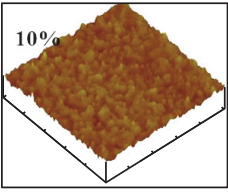

$\mathrm{RMS} \sim 4.6 \mathrm{~nm}$

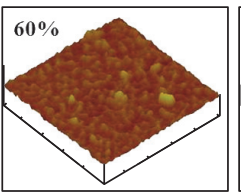

$\mathrm{RMS} \sim 6 \mathrm{~nm}$

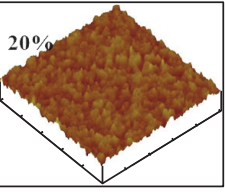

$\mathrm{RMS} \sim 4.9 \mathrm{~nm}$

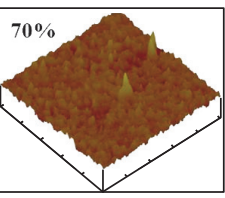

RMS $\sim 6.7 \mathrm{~nm}$

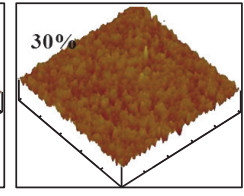

$\mathrm{RMS} \sim 5.2 \mathrm{~nm}$

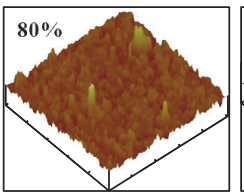

$\mathrm{RMS} \sim 6.9 \mathrm{~nm}$

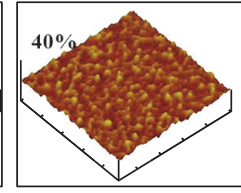

$\mathrm{RMS} \sim 5.5 \mathrm{~nm}$

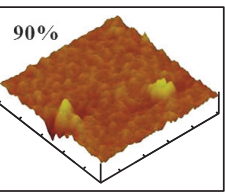

$\mathrm{RMS} \sim 7.2 \mathrm{~nm}$

(a)

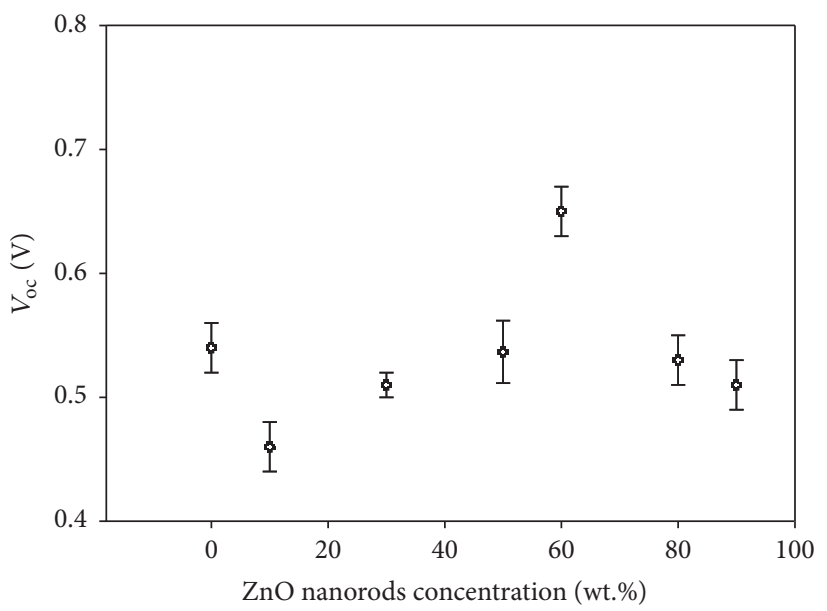

(A)

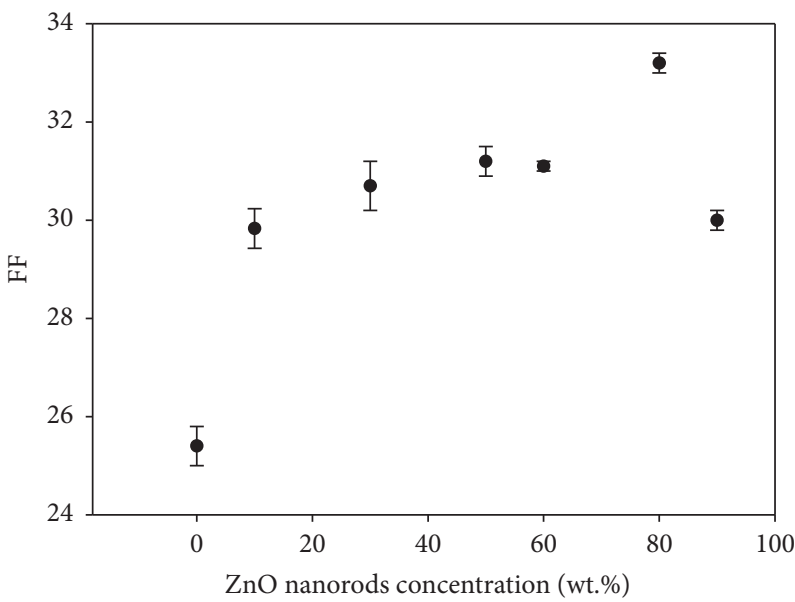

(C)

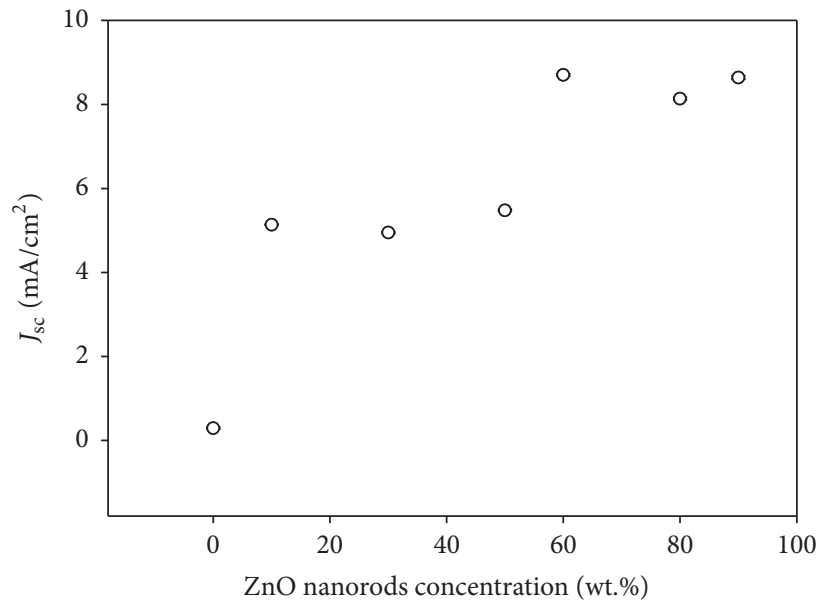

(B)

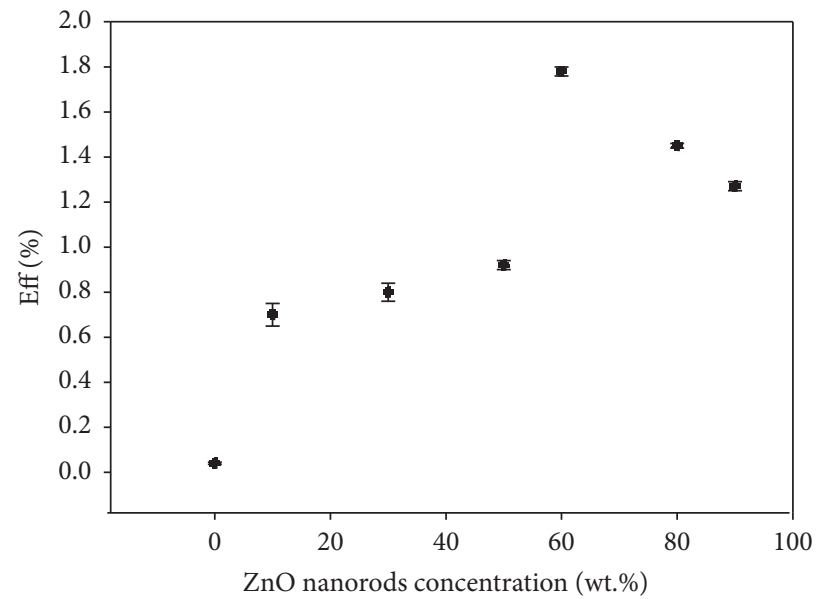

(D)

(b)

Figure 3: (a) Photoactive layer' surface morphology of solar cells with different composite loading amount of ZnO-Nrod/[ZnO-Nrod + $\mathrm{P} 3 \mathrm{HT}] \mathrm{wt} \%$. (b) Device's parameters with different composite loading amount of ZnO-Nrod/[ZnO-Nrod + P3HT] wt\%.

donor HOMO and acceptor LUMO [23], the application of polymers with low band gaps as donors typically decreases $V_{\text {oc }}$, and a trade-off between light absorption and electrical properties is realized for both standard and inverted device geometries. Influences of the sunlight' harvesting on the device performance were studied. Table 2 shows that the open circuit voltage $\left(V_{\text {oc }}\right)$ is slightly decreased from about $\sim 0.6$ to $0.5 \mathrm{eV}$ when the lower-band-gap energy polymer was used, but the short circuit current density gradually increased. 


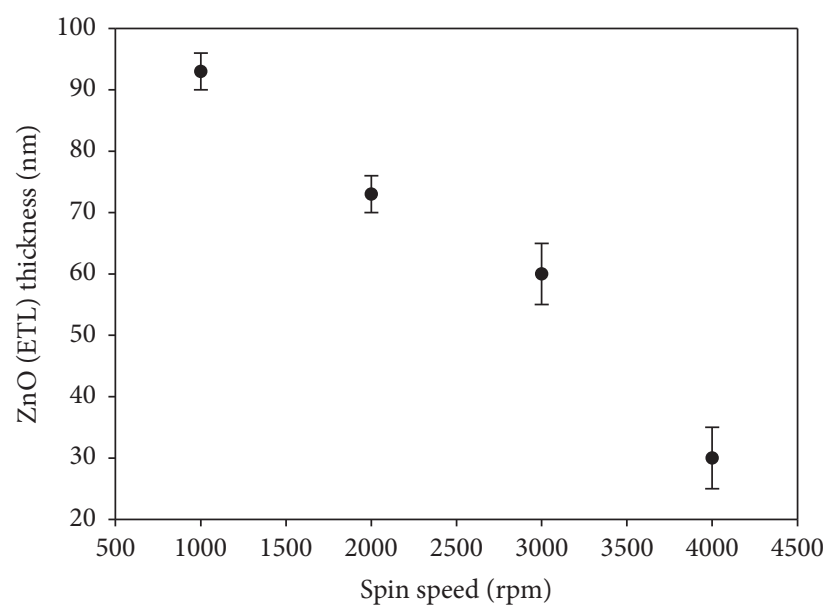

(a)
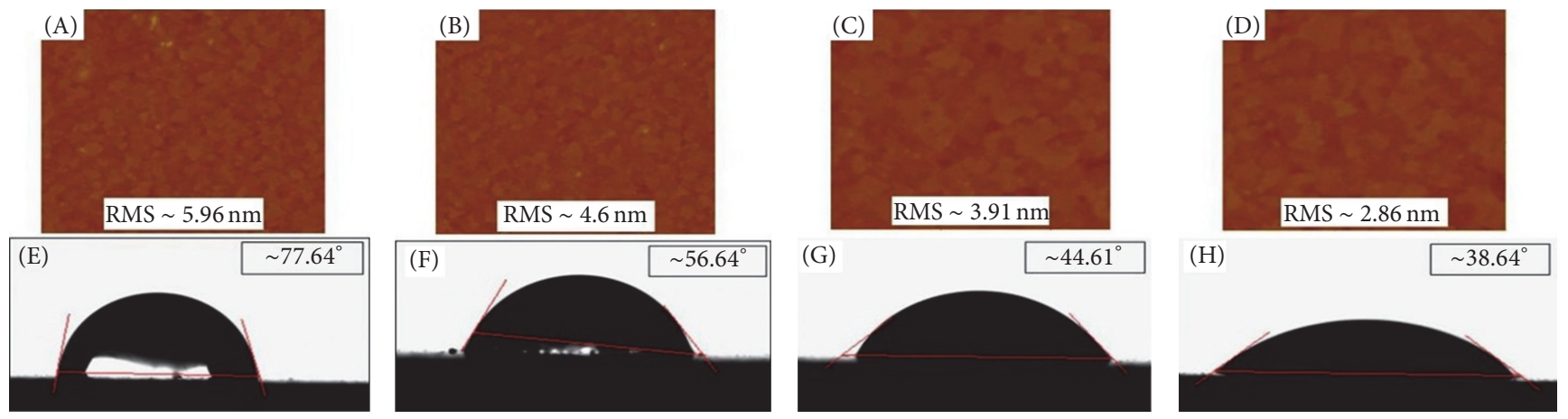

(b)

FIGURE 4: (a) The thickness and (b) surface roughness of electron transport layer (ETL) (ZnO nanoparticle) with a varying spin speed from 1000 to 4000 rounds per minute (rpm).

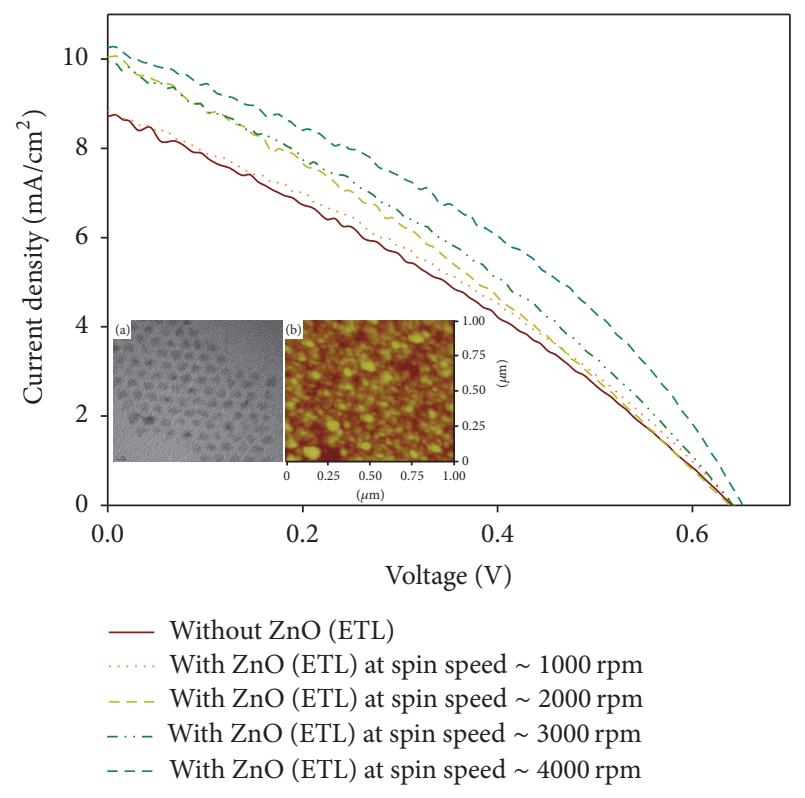

Figure 5: ((a), (b)) TEM image (inset) of $\mathrm{ZnO}$ nanoparticles and surface morphology of $\mathrm{ZnO}$ NPs/ITO film and $J-V$ characteristic of device with and without electron transport layer as the junction of spin speed (round per minute).
Figure 6 shows the $J-V$ curves of the $\mathrm{ZnO}-\mathrm{Nrods} /$ polymer devices; the efficiency of the devices was found to be enhanced from $\sim 2.25 \%\left(J_{\mathrm{sc}} \sim 10.26 \mathrm{~mA} / \mathrm{cm}^{2}\right)$ of the $\mathrm{ZnO} / \mathrm{P} 3 \mathrm{HT}$ cell to $\sim 2.54 \%\left(J_{\mathrm{sc}} \sim 12.62 \mathrm{~mA} / \mathrm{cm}^{2}\right)$ of the $\mathrm{ZnO} / \mathrm{PCPDTBT}$ cell, with the maximum efficiency of about $\sim 2.9 \%\left(J_{\mathrm{sc}} \sim 14.9 \mathrm{~mA} / \mathrm{cm}^{2}\right)$ of the $\mathrm{ZnO} / \mathrm{PTB} 7$ cell. The enhanced efficiency was mainly due to the increase in the short circuit current from 10.26 to $14.9 \mathrm{~mA} / \mathrm{cm}^{2}$, which indicates an increase in the light absorption by PCPDTBT and PBT7 polymers, because the absorption wavelength is extended further within the visible region. Previous studies reported that the power conversion efficiency of the $\mathrm{ZnO}$ Nrods solar cells was very low $(\sim 0.2$ and $\sim 0.9 \%)$, because the device fabrication process is not well optimized $[24,25]$. ptype semiconductor ligand modification of $\mathrm{ZnO}$ nanorods is used to increase the device performance. The porphyrin and phthalocyamine molecules were incorporated at hybrid $\mathrm{p}-\mathrm{n}$ junction interface; however, they found that adding of ligand modified $\mathrm{ZnO}$-Nrods to the polymer leads to composite blends with poor photocurrent generation efficiency although the nanorods were highly dispersed inside the polymer. Zhong et al. [25] reported that they use Z907modified $\mathrm{ZnO}$ nanorods and polymer, the effects of Z907 grafting on the light absorption, carriers transport, and 


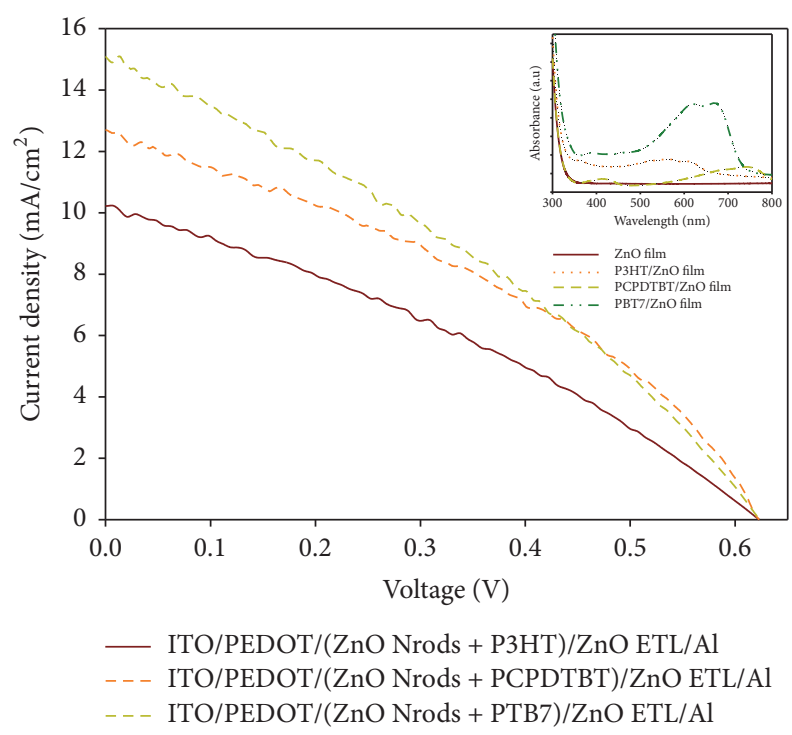

Figure 6: Absorption spectrum (inset) of $\mathrm{ZnO}-\mathrm{Nrod}$ and ( $\mathrm{ZnO}$ Nrod + polymers) films and $J-V$ characteristic of device with electron transport layer (ETL) and different low band gap energy polymers.

active layer surface morphology. But the device's conversion efficiency is still quite low in comparison with the previous inorganic hybrid solar cells (recorded efficiency of $3 \%$ ). Our cell performance with efficiency of $\sim 2.9 \%$ is only compared to the recorded values reported for inorganic hybrid solar cells. Our device fabrication is quite different from previous reports and the efficiency of the cell with pure and random nanorods is bigger than $\mathrm{ZnO}$ NPs- and ligand modified $\mathrm{ZnO}$ nanorod/polymer cells.

\section{Conclusions}

In summary, we prepared high-performance inorganic $\mathrm{BHJ}$ solar cells with the addition of an electron transport layer ( $\mathrm{ZnO}$ layer) by using a high-light-absorption polymer with low band gap energy, such as PCPDTBT and PTB7. We obtained power conversion efficiency as high as $\sim 3 \%$ for the structure based on ZnO-Nrods and PTB7, by using a $\mathrm{ZnO}$ nanoparticle ETL. Therefore, this investigation opens new avenues for the structure design and development of electron transport materials for high-performance solar cells and many other optoelectronic devices.

\section{Competing Interests}

The authors declare that they have no competing interests.

\section{Authors' Contributions}

Nguyen Tam Nguyen Truong and Hoa Nguyen contributed equally to this work.

\section{Acknowledgments}

This work was supported by "Human Resources Program in Energy Technology" of the Korea Institute of Energy Technology Evaluation and Planning (KETEP), granted financial resource from the Ministry of Trade, Industry \& Energy, Republic of Korea (no. 20154030200760).

\section{References}

[1] Y.-S. Cho and Y.-D. Huh, "Preparation and optical properties of green-emitting $\mathrm{BaMoO}_{4}: \mathrm{Tb}^{3+}, \mathrm{Na}^{+}$nanophosphors for transparent displays," Electronic Materials Letters, vol. 10, no. 6, pp. 1185-1189, 2014.

[2] D. A. Van Den Ende, R. Hendriks, R. Cauchois, and W. A. Groen, "Large area photonic flash soldering of thin chips on flex foils for flexible electronic systems: in situ temperature measurements and thermal modelling," Electronic Materials Letters, vol. 10, no. 6, pp. 1175-1183, 2014.

[3] N. T. N. Truong and C. Park, "Enhancement of CdSe/Poly(3hexylthiophene) bulk heterojunction solar cell efficiency by surface ligand exchange and thermal treatment," Japanese Journal of Applied Physics, vol. 51, no. 10, Article ID 10NE27, 2012.

[4] N. C. Greenham, X. Peng, and A. P. Alivisatos, "Charge separation and transport in conjugated-polymer/semiconductornanocrystal composites studied by photoluminescence quenching and photoconductivity," Physical Review B, vol. 54, no. 24, pp. 17628-17637, 1996.

[5] A. A. R. Watt, D. Blake, J. H. Warner et al., "Lead sulfide nanocrystal: conducting polymer solar cells," Journal of Physics D: Applied Physics, vol. 38, no. 12, pp. 2006-2012, 2005.

[6] W. U. Huynh, J. J. Dittmer, and A. P. Alivisatos, "Hybrid nanorod-polymer solar cells," Science, vol. 295, no. 5564, pp. 2425-2427, 2002.

[7] B. Sun, E. Marx, and N. C. Greenham, "Photovoltaic devices using blends of branched CdSe nanoparticles and conjugated polymers," Nano Letters, vol. 3, no. 7, pp. 961-963, 2003.

[8] B. O’Regan and M. Grätzel, "A low-cost, high-efficiency solar cell based on dye-sensitized colloidal $\mathrm{TiO}_{2}$ films," Nature, vol. 353, no. 6346, pp. 737-740, 1991.

[9] S. A. Haque, S. Koops, N. Tokmoldin et al., "A multilayered polymer light-emitting diode using a nanocrystalline metaloxide film as a charge-injection electrode," Advanced Materials, vol. 19, no. 5, pp. 683-687, 2007.

[10] R. Cinnsealach, G. Boschloo, S. N. Rao, and D. Fitzmaurice, "Electrochromic windows based on viologen-modified nanostructured TiO2 films," Solar Energy Materials and Solar Cells, vol. 55, no. 3, pp. 215-223, 1998.

[11] C. G. Granqvist, "Electrochromic tungsten oxide films: review of progress 1993-1998," Solar Energy Materials and Solar Cells, vol. 60, no. 3, pp. 201-262, 2000.

[12] Y.-M. Lee, C.-M. Huang, H.-W. Chen, and H.-W. Yang, "Low temperature solution-processed $\mathrm{ZnO}$ nanorod arrays with application to liquid ethanol sensors," Sensors and Actuators, A: Physical, vol. 189, pp. 307-312, 2013.

[13] L.-W. Ji, S.-M. Peng, J.-S. Wu, W.-S. Shih, C.-Z. Wu, and I.-T. Tang, "Effect of seed layer on the growth of well-aligned $\mathrm{ZnO}$ nanowires," Journal of Physics and Chemistry of Solids, vol. 70, no. 10, pp. 1359-1362, 2009. 
[14] Z. H. Ibupoto, K. Khun, M. Eriksson et al., "Hydrothermal growth of vertically aligned $\mathrm{ZnO}$ nanorods using a biocomposite seed layer of $\mathrm{ZnO}$ nanoparticles," Materials, vol. 6, no. 8, pp. 3584-3597, 2013.

[15] W. J. E. Beek, M. M. Wienk, and R. A. J. Janssen, "Efficient hybrid solar cells from zinc oxide nanoparticles and a conjugated polymer," Advanced Materials, vol. 16, no. 12, pp. 10091013, 2004.

[16] W. J. E. Beek, M. M. Wienk, M. Kemerink, X. Yang, and R. A. J. Janssen, "Hybrid zinc oxide conjugated polymer bulk heterojunction solar cells," Journal of Physical Chemistry B, vol. 109, no. 19, pp. 9505-9516, 2005.

[17] D. C. Olson, S. E. Shaheen, R. T. Collins, and D. S. Ginley, “The effect of atmosphere and $\mathrm{ZnO}$ morphology on the performance of hybrid poly(3-hexylthiophene)/ZnO nanofiber photovoltaic devices," Journal of Physical Chemistry C, vol. 111, no. 44, pp. 16670-16678, 2007.

[18] I. Litzov and C. J. Brabec, "Development of efficient and stable inverted bulk heterojunction (BHJ) solar cells using different metal oxide interfaces," Materials, vol. 6, no. 12, pp. 5796-5820, 2013.

[19] M. A. Ibrahem, H.-Y. Wei, M.-H. Tsai, K.-C. Ho, J.-J. Shyue, and C. W. Chu, "Solution-processed zinc oxide nanoparticles as interlayer materials for inverted organic solar cells," Solar Energy Materials and Solar Cells, vol. 108, pp. 156-163, 2013.

[20] T. Hu, F. Li, K. Yuan, and Y. Chen, "Efficiency and air-stability improvement of flexible inverted polymer solar cells using $\mathrm{ZnO} /$ poly(ethylene glycol) hybrids as cathode buffer layers," ACS Applied Materials and Interfaces, vol. 5, no. 12, pp. 57635770, 2013.

[21] J. S. Bhat, A. S. Patil, N. Swami et al., "Electron irradiation effects on electrical and optical properties of sol-gel prepared ZnO films," Journal of Applied Physics, vol. 108, no. 4, Article ID 043513, 2010.

[22] M. Ohyama, H. Kozuka, and T. Yoko, "Sol-gel preparation of transparent and conductive aluminum-doped zinc oxide films with highly preferential crystal orientation," Journal of the American Ceramic Society, vol. 81, no. 6, pp. 1622-1632, 1998.

[23] C. Deibel and V. Dyakonov, "Polymer-fullerene bulk heterojunction solar cells," Reports on Progress in Physics, vol. 73, no. 9, Article ID 096401, 2010.

[24] S. Ben Dkhil, M. Gaceur, W. Dachraoui et al., "P-type semiconductor surfactant modified zinc oxide nanorods for hybrid bulk heterojunction solar cells," Solar Energy Materials \& Solar Cells, vol. 159, pp. 608-616, 2017.

[25] M. Zhong, D. Sheng, C. Li, S. Xu, and X. Wei, "Hybrid bulk heterojunction solar cells based on poly (3-hexylthiophene) and Z907-modified ZnO nanorods," Solar Energy Materials \& Solar Cells, vol. 121, pp. 22-27, 2014. 

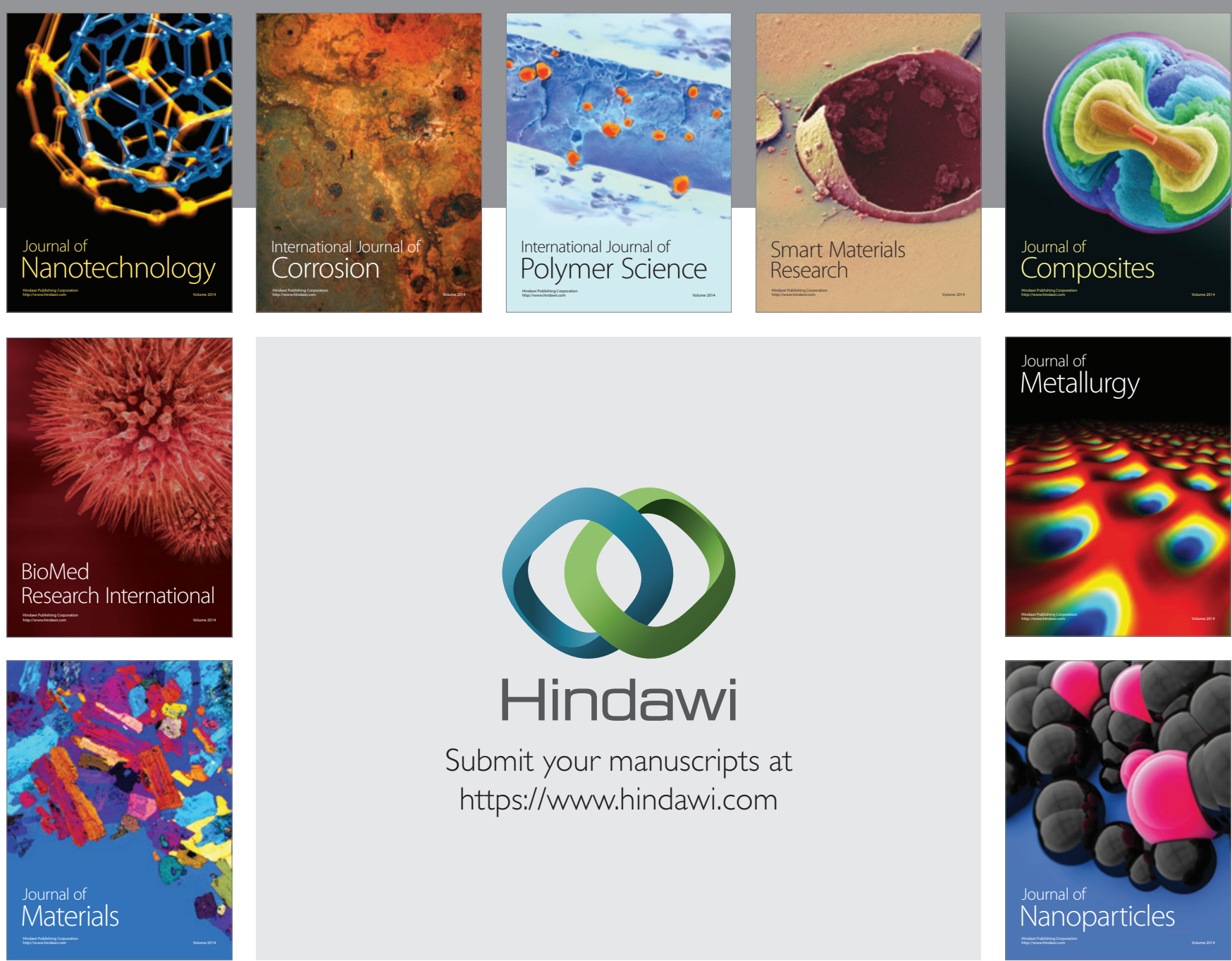

\section{Hindawi}

Submit your manuscripts at

https://www.hindawi.com

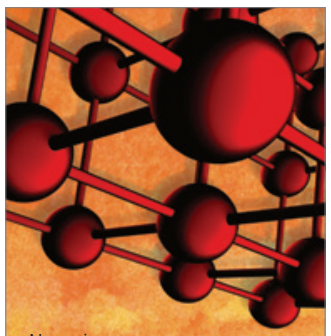

Materials Science and Engineering
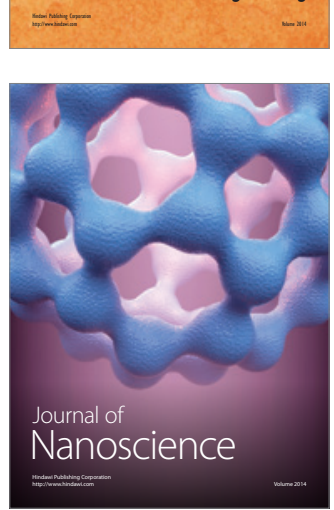
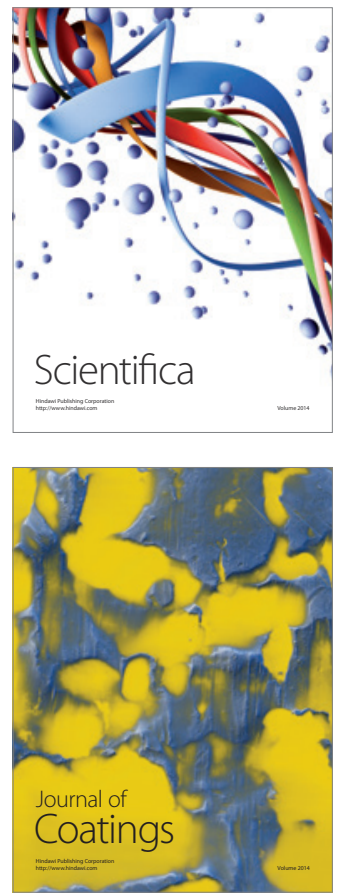
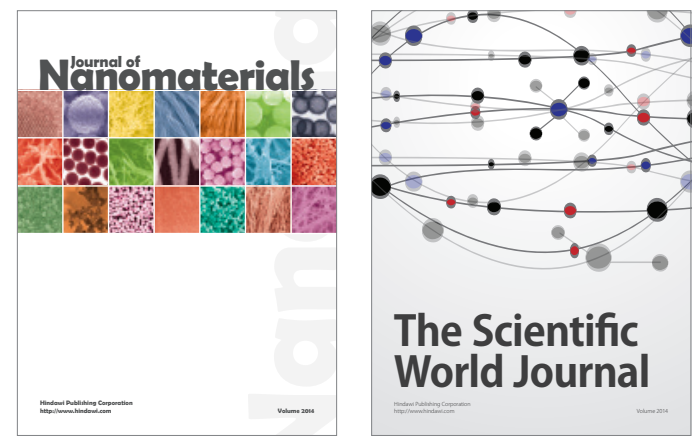

The Scientific World Journal
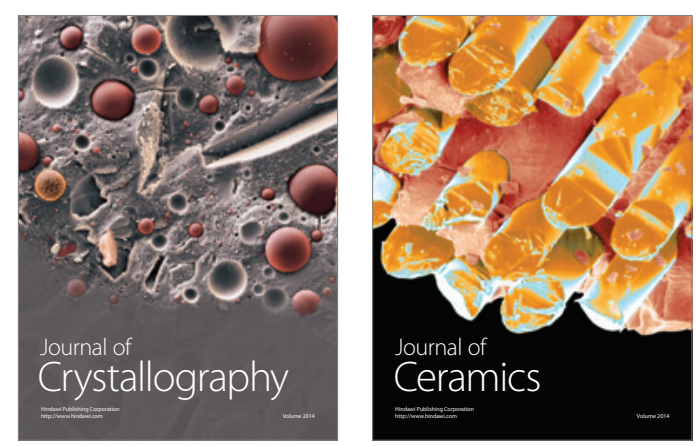
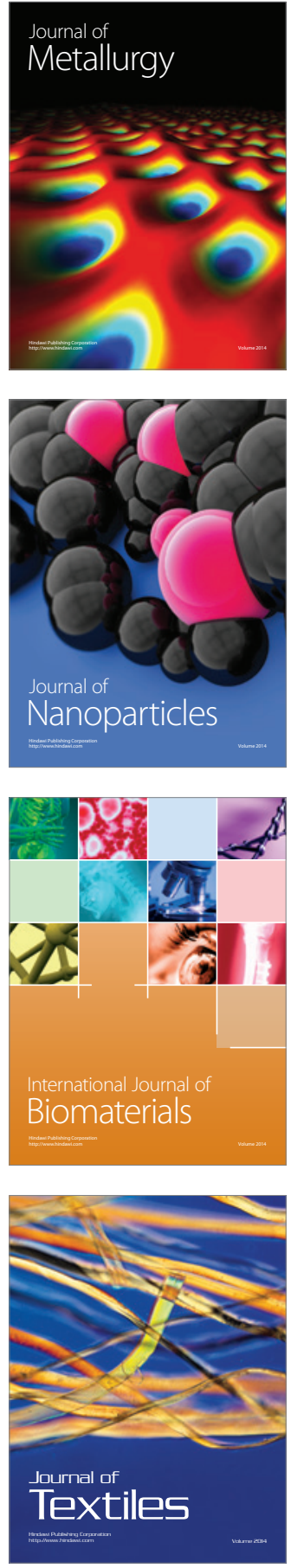